\title{
Atmospheric circulation anomalies during two persistent north american droughts: 1932-1939 and 1948-1957
}

\author{
Benjamin I. Cook • Richard Seager • \\ Ron L. Miller
}

Received: 5 November 2009/ Accepted: 22 March 2010

(C) US government 2010

\begin{abstract}
We use an early twentieth century (1908-1958) atmospheric reanalysis, based on assimilation of surface and sea level pressure observations, to contrast atmospheric circulation during two periods of persistent drought in North America: 1932-1939 (the 'Dust Bowl') and 19481957. Primary forcing for both droughts is believed to come from anomalous sea surface temperatures (SSTs): a warm Atlantic and a cool eastern tropical Pacific. For boreal winter (October-March) in the 1950s, a stationary wave pattern originating from the tropical Pacific is present, with positive centers over the north Pacific and north Atlantic ocean basins and a negative center positioned over northwest North America and the tropical/subtropical Pacific. This wave train is largely absent for the 1930s drought; boreal winter height anomalies are organized much more zonally, with positive heights extending across northern North America. For boreal summer (April-September) during the 1930s, a strong upper level ridge is centered over the Great Plains; this feature is absent during the 1950s and appears to be linked to a weakening of the Great Plains low-level jet (GPLLJ). Subsidence anomalies are co-located over the centers of each drought: in the central Great Plains for the 1930s and in a band extending from the southwest to the southeastern United States for the 1950s. The location and intensity of this subsidence during the 1948-1957 drought is a typical response to a cold eastern tropical Pacific, but for 1932-1939 deviates in
\end{abstract}

B. I. Cook $(\bowtie) \cdot$ R. Seager

Lamont-Doherty Earth Observatory, 61 Route 9W,

Palisades, NY 10964, USA

e-mail: bc9z@1deo.columbia.edu

B. I. Cook $\cdot$ R. L. Miller

NASA Goddard Institute for Space Studies,

2880 Broadway, New York, NY 10025, USA terms of the expected intensity, location, and spatial extent. Overall, circulation anomalies during the 1950s drought appear consistent with the expected response to the observed SST forcing. This is not the case for the 1930s, implying some other causal factor may be needed to explain the Dust Bowl drought anomalies. In addition to SST forcing, the 1930s were also characterized by massive alterations to the land surface, including regional-scale devegetation from crop failures and intensive wind erosion and dust storms. Incorporation of these land surface factors into a general circulation model greatly improves the simulation of precipitation and subsidence anomalies during this drought, relative to simulations with SST forcing alone. Even with additional forcing from the land surface, however, the model still has difficulty reproducing some of the other circulation anomalies, including weakening of the GPLLJ and strengthening of the upper level ridge during AMJJAS. This may be due to either weaknesses in the model or uncertainties in the boundary condition estimates. Still, analysis of the circulation anomalies supports the conclusion of an earlier paper (Cook et al. in Proc Natl Acad Sci 106:4997, 2009), demonstrating that land degradation factors are consistent with the anomalous nature of the Dust Bowl drought.

Keywords Drought - Dynamics · Dust Bowl · Great Plains

\section{Introduction}

Recent years have seen rapid advances in our understanding of the dynamical mechanisms governing global hydroclimatic variability (Hoerling and Kumar 2003; Schubert et al. 2009; Seager et al. 2003, 2005a; Seager 
2007). Modeling and empirical studies have revealed robust teleconnections between variations in sea surface temperatures (SSTs) and precipitation and temperature patterns in distant regions, highlighting the possibility for improved prediction of climate on decadal timescales (Keenlyside et al. 2008). North America (NA) is one region where there has been a great degree of success simulating hydroclimatic variability using SST forcing. Much of the variance and persistence in drought and pluvial events over NA can be dynamically linked to SST anomalies and their associated climate patterns originating in the tropical Pacific (El Niño Southern Oscillation, ENSO) and the north Atlantic (Atlantic Multidecadal Oscillation, AMO).

On interannual to decadal timescales, ENSO is the major global driver of hydroclimatic variability in the tropics, subtropics, and midlatitudes, including NA (Herweijer et al. 2006, 2007; Seager et al. 2005b; Seager 2007). When the eastern tropical Pacific is colder than normal (i.e., La Nina phase of ENSO), precipitation over southern NA is suppressed, with the drying arising from from two separate, but ultimately complementary, dynamical mechanisms. The first is a zonally and hemispherically symmetric mean meridional circulation response, driven by pan-tropical cooling originating from the cold tropical Pacific SSTs (Seager et al. 2003, 2005a). Cooler tropics lead to a reduction in equator-to-pole temperature and pressure gradients and a poleward contraction of the westerly jets. Transient eddies penetrate less deeply into the tropics and deposit their momentum in the midlatitudes, forcing mass convergence in the upper atmosphere which, to satisfy continuity, drives anomalous descent, suppressing precipitation in midlatitude zonal bands in both hemispheres. The second mechanism is a stationary wave emanating from the tropical Pacific, often associated with the Pacific North America pattern (PNA) (Trenberth et al. 1998; Wallace and Gutzler 1981). During La Nina, this stationary wave is characterized by positive height anomalies in the north Pacific and along the eastern coast of NA, with negative height anomalies over the subtropical Pacific and extending southeast from Alaska and the Pacific Northwest (Trenberth et al. 1998). Both mechanisms lead to drying in the southwestern and southeastern regions of NA.

The direct influence of ENSO on NA hydroclimate is strongest during boreal winter and is weaker during the warm season, but can be enhanced indirectly through soil moisture anomalies and Atlantic SSTs. Soil moisture acts as a seasonal bridge, providing a source of system memory at the land surface and allowing cold season moisture anomalies to carry over into the warm season, prolonging and often intensifying drought anomalies (Schubert et al. 2004a; Wang et al. (2010)). The Pacific can also act indirectly during the warm season through it's influence on Atlantic SSTs (Enfield and Mayer 1997), which have a stronger impact, relative to ENSO, during the warm season (Kushnir et al. 2010; Wang et al. 2010). There is some speculation that forcing from the extratropical north Pacific may also be an important driver of NA hydroclimatic variability, especially on interdecadal time scales, manifesting as the Pacific Decadal Oscillation (PDO) (Mantua et al. 1997; Mantua and Hare 2002; McCabe et al. 2004, 2008). However, the underlying dynamics of Pacific decadal variability are poorly understood (McCabe et al. 2008), and the associated atmospheric anomalies look quite similar to responses due to ENSO forcing. This has led to some speculation that Pacific decadal variability may be partially or wholly an extratropical low frequency expression of ENSO (Mantua and Hare 2002; McCabe et al. 2008).

More recently, evidence has emerged for a significant influence of north Atlantic SST variability on NA climate (Kushnir et al. 2010; McCabe et al. 2004, 2008; Wang et al. 2006). At multidecadal frequencies, this SST variability is linked with the AMO which is thought to be driven by variations in the strength of the ocean meridional overturning circulation (Enfield et al. 2001; Sutton and Hodson 2005). When North Atlantic SSTs are warmer than normal, precipitation is typically reduced over NA, although the specific mechanisms remain elusive (McCabe et al. 2004, 2008). As with the north Pacific, SSTs in the Atlantic are known to be influenced by ENSO (Enfield and Mayer 1997), and so Atlantic variability may not be completely independent from ENSO-forced variability (Enfield et al. 2001; Sutton and Hodson 2005). The influence of north Atlantic SSTs on NA hydroclimate is most completely understood during the boreal summer (Enfield et al. 2001; Sutton and Hodson 2005, 2007), though recent work suggests the Atlantic impact persists throughout the year (Kushnir et al. 2010; Wang et al. 2010).

When forced with observed SSTs, atmospheric general circulation models (GCMs) reliably reproduce the intensity, duration, and spatial expression of most instrumental era NA droughts. This includes the Civil War drought (1856-1865), the 1870s drought (1870-1877), the 1890s drought (1890-1896), the 1950s drought (1948-1957), and the most recent turn of the twenty-first century drought (1998-2004) (Herweijer et al. 2006; Seager et al. 2005b; Seager 2007). The notable exception, however, is the 'Dust Bowl' drought (1932-1939). While there has been some success simulating the onset of the Dust Bowl and the general drought pattern (Schubert et al. 2004a, b; Seager et al. 2008), few models are able to reproduce the proper intensity or location of this drought using SST forcing alone. The difficulty may be due to the exceptional land degradation that occurred during the Dust Bowl, conditions 
unique among the instrumental droughts (Hansen and Libecap 2004). The land degradation took the form of extensive crop failures throughout the Great Plains, leading to massive wind erosion and dust storm activity that was unprecedented for the historical period. Recent modeling work suggests that the feedbacks from the dust aerosols and the loss of vegetation played a critical role in driving the anomalous temperature and precipitation patterns (Cook et al. 2008, 2009; Koven 2006).

If SST forcing alone is insufficient, and other mechanisms (such as changes at the land surface) are required to explain the anomalous nature of the 1930s Dust Bowl, this should be apparent in the dynamical fields, and it will be expected that circulation during the 1930s will be noticeably different from circulation during droughts dominated by SST forcing, such as the 1950s drought. Up until recently, a full dynamical investigation of the 1930s has been difficult because of the paucity of atmospheric data (other than precipitation and temperature) from this time period, although some preliminary analyses have been conducted (Brönnimann et al. 2009). Recently, however, a new reanalysis product has become available, covering the time period from 1908-1958, a span encompassing both the 1930s drought (1932-1939) and the 1950s drought (1948-1957). For this study, we will use variables from this reanalysis (geopotential height, pressure vertical velocity, winds, specific humidity) to investigate two questions: (1) How different is the atmospheric circulation between the 1930s (1932-1939) and 1950s (1948-1957) North American droughts? and (2) How well can the 1930s drought be simulated by a GCM forced only by observed SSTs, and is land surface degradation required to reproduce the circulation anomalies and drought pattern?

\section{Data and methods}

In order to facilitate comparisons between the model results and the COMPO reanalysis, we chose a common baseline period (1921-1929) for the calculation of anomalies. This period was relatively free of any major persistent drought or pluvial events, representing a largely 'normal' period in NA hydroclimate, and is independent from both drought periods we are interested in investigating. It is also a common baseline period available from both the model runs (1921-1939) and the reanalysis (19081958).

\subsection{Early twentieth century reanalysis (1908-1958)}

For this study, we use a recently released atmospheric reanalysis for the first half of the twentieth century, 19081958 (Compo et al. 2006, hereafter, COMPO), a product conceptually similar to other data assimilation products, such as the NCEP/NCAR reanalysis (Kalnay et al. 1996). The COMPO reanalysis is generated using an ensemble filter approach. Ensembles of short-term forecasts are generated using the state of the art atmospheric general circulation model from the NCEP operational Climate Forecast System (Saha et al. 2006), operating on an irregular Gaussian grid corresponding to a T62 horizontal resolution (grid spacing approximately $2^{\circ} \times 2^{\circ}$ ), with 28 levels in the vertical, extending to a model top of $0.2 \mathrm{hPa}$. The atmosphere model is driven by time-evolving sea surface temperatures and sea ice distributions from the HadISST1.1 dataset (Rayner et al. 2003), which we also use to compare and contrast SST patterns during the two droughts. The model assimilates observations of surface pressure and sea level pressure every six hours from the International Surface Pressure Databank version 1.1 and ICOADS version 2.4. Variables available from the reanalysis at the various pressure levels are geopotential heights, temperature, horizontal winds, pressure vertical velocities, and specific and relative humidity.

For our region of interest (NA), the COMPO reanalysis compares favorably against independent data and analyses, including an independent statistical reconstruction of early twentieth century geopotential heights (Griesser et al. 2008) and gridded precipitation anomalies (Mitchell and Jones 2005). The Griesser et al. (2008) product is a statistical reconstruction of geopotential height and temperature fields from historical upper air and surface data. For their reconstruction of geopotential heights, Griesser et al. (2008) show high skill over their validation period during the winter months, but much less skill during the summer. For the full overlapping period and our region of interest (1921-1957, averaged over $180^{\circ} \mathrm{W}-40^{\circ} \mathrm{W}$ and $20^{\circ} \mathrm{N}-$ $60^{\circ} \mathrm{N}$ ), geopotential heights between COMPO and Griesser et al. (2008) are highly correlated, especially during the winter. For October-March (ONDJFM), at 850/500/200 $\mathrm{hPa}$, the Pearson correlations between the two products are 0.88/0.80/0.45 (all significant at $p<0.05$ ); for these same levels during April-September (AMJJAS) the correlations are 0.48/0.38/0.56 (all significant at $p<0.05$ ). Again, we note that the Griesser et al. (2008) product has significantly lower skill during the warm season, so a reduction in the correlation of the two products is not especially surprising. Both products also show similar geopotential height anomalies during our time periods of interest, including the wave train during ONDJFM, 1948-1957 and the upper level ridge during AMJJAS, 1932-1939; these features will be discussed later. Pressure vertical velocity anomalies from COMPO match well with observed precipitation anomalies from the CRU 2.1 climate grids (Mitchell and Jones 2005) for the two drought periods, with subsidence anomalies coincident with negative precipitation anomalies 
(discussed later). Finally, we note that the COMPO reanalysis has already been used, successfully, to look at other early twentieth century circulation features (Wood and Overland 2009).

For this study we will be focusing on the NA region, a relatively data rich area that should provide more reliable estimates than other, data poor areas, such as the Southern Ocean or Africa. We use monthly average values of the major dynamical variables (geopotential heights, horizontal winds, and pressure vertical velocity) and organize the analysis into two seasons: boreal autumn/winter (OctoberMarch, ONDJFM) and spring/summer (April-September, AMJJAS). There is precedent in the drought literature for an ONDJFM/AMJJAS seasonal division (Kushnir et al. 2010; Seager et al. 2005b; Seager 2007), and we found that our results and conclusions were relatively insensitive to the exact definition of our cold and warm seasons.

\subsection{Model simulations}

The model output comes from a series of simulations conducted with the NASA Goddard Institute for Space Studies (NASA GISS) atmosphere general circulation model, ModelE (Cook et al. 2009). In the SST-ONLY experiments, the authors forced a five-member ensemble (each member starting from different initial conditions) for the period 1932-1939 using only SSTs observed during this period. In the SST + LAND experiments, the authors ran an additional five member ensemble for the same period, incorporating not only observed SST information, but also estimates of dust aerosols and land cover changes. The land cover changes are integrated into the model by converting crop areas over the Great Plains to bare soil. The dust aerosols are included by adding a dust source over the Great Plains and allowing the model to deflate the dust into the atmosphere, where it can interact radiatively. Additional details on the experiments, including how the boundary forcing was estimated, are contained in Cook et al. (2009). For more detailed discussions of GISS ModelE formulations and performance, readers are referred to the available literature (Hansen et al. 2007; Miller et al. 2006; Schmidt et al. 2006). Comparing the model precipitation anomalies against available observations, Cook et al. (2009) concluded that inclusion of surface changes and dust aerosols improved the simulated intensity, location, and spatial extent of the drought, compared to simulations with SST forcing only. At the time, however, a comparison of the circulation as characterized by geopotential heights and vertical velocities was not possible because of the lack of available data.

To determine to what extent the dynamics in the COMPO reanalysis represent a response to SST forcing (as opposed to either noise or forcing from other factors), we also use a separate series of GCM experiments forced by idealized patterns of SST forcing in the tropical Pacific and Atlantic basins (Schubert et al. 2009). These simulations are described in more detail in Sect. 3.

\subsection{Other data}

Monthly gridded precipitation data are from the Climate Research Unit (CRU) at the University of East Anglia (Mitchell and Jones 2005). The CRU data are statistically interpolated from monthly station observations to a regular terrestrial grid at half degree spatial resolution and monthly temporal resolution, covering the time period 1901-2002. Gridded SST anomalies are taken from the HadISST1.1 dataset (Rayner et al. 2003), the same dataset used as part of the COMPO reanalysis and also used to force the aforementioned GISS model simulations (Cook et al. 2009). Monthly climate indices for the PDO, AMO, and ENSO (NINO 3.4) are taken from various sources (Enfield et al. 2001; Mantua et al. 1997; Trenberth et al. 1997); these indices have been standardized (zero mean, unit standard deviation) to facilitate comparisons.

\section{Results}

\subsection{Precipitation and SST anomalies}

Composite SST anomalies for the two drought periods show that both droughts were associated with warmer than normal north Atlantic SSTs and a cooler than normal eastern tropical Pacific (Fig. 1). Pacific anomalies are cooler and much more widespread during the 1950s, while north Atlantic anomalies are similar between the two droughts. The central north Pacific is anomalously warm during the 1950s, indicative of a negative phase PDO during this latter drought. Differences in the level of forcing can be seen even more clearly when climate indices during the droughts are averaged across years (Table 1). For example, NINO 3.4 and PDO index anomalies during ONDJFM are over twice the magnitude during the 19481957 drought, compared to 1932-1939. AMO anomalies are comparable, although the AMJJAS anomalies are stronger during 1932-1939 than 1948-1957. Dividing the Dust Bowl drought into two periods (1932-1934 and 19351939) shows the transient nature of the tropical Pacific forcing. NINO 3.4 anomalies were much larger during the earlier part of the drought, comparable to anomalies during the 1950s drought, and all but disappeared during the latter part. This implies that La Nina may have been important for the onset of the Dust Bowl drought (Seager et al. 2008), but may not be able to fully explain the drought persistence or the mean drought pattern. 

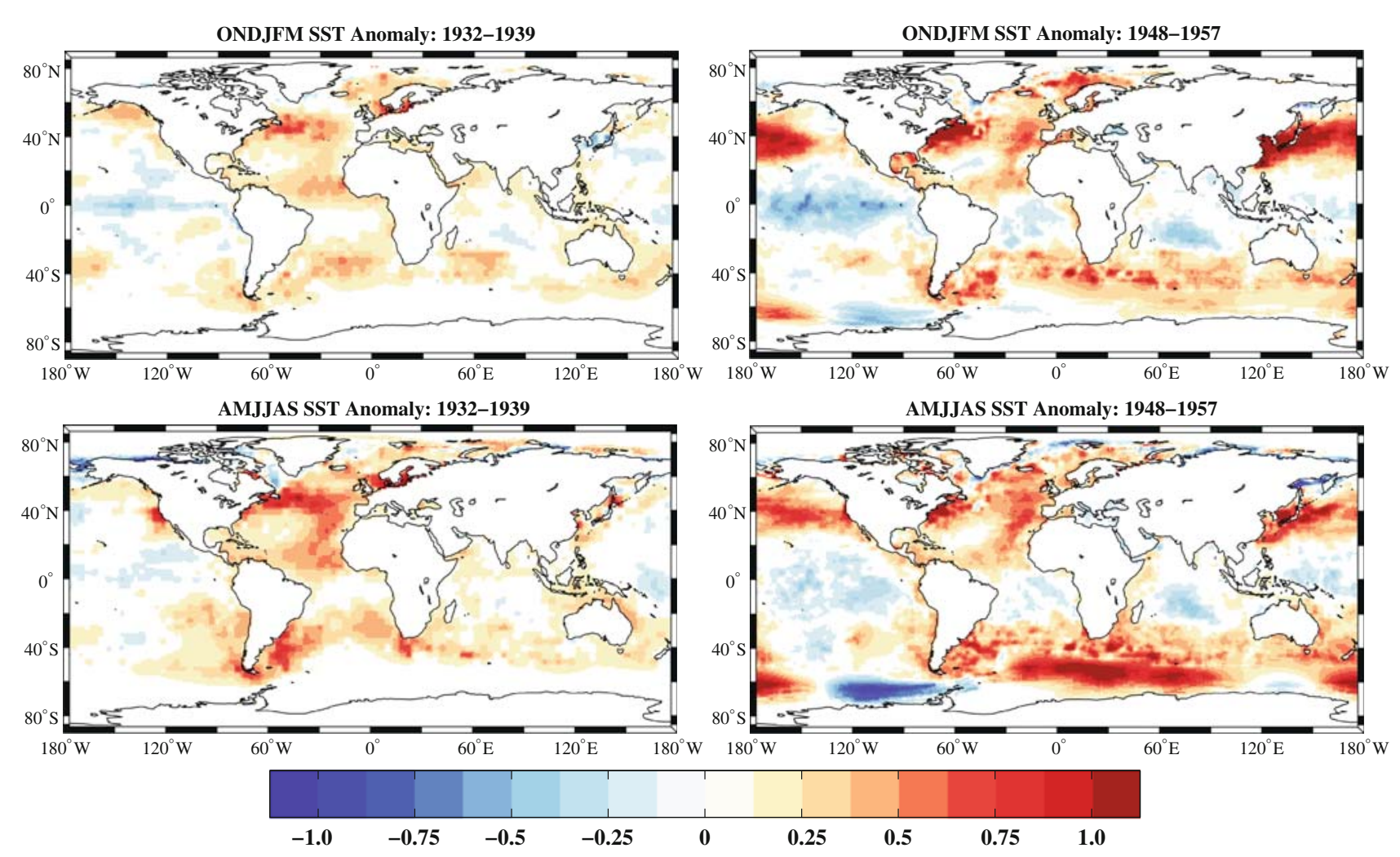

Fig. 1 Background SST anomalies $\left({ }^{\circ} \mathrm{C}\right)$ for 1932-1939 and 1948-1957, relative to 1921-1929. Anomalies for boreal winter (October-March, ONDJFM) and boreal summer (April-September, AMJJAS) are shown

Table 1 Average NINO 3.4, AMO, and PDO index anomalies for boreal winter (ONDJFM) and summer (AMJJAS) seasons during the two droughts

\begin{tabular}{lllr}
\hline & NINO 3.4 & AMO & PDO \\
\hline ONDJFM & & & \\
1932-1934 & -0.48 & 0.73 & 0.04 \\
$1935-1939$ & -0.07 & 0.79 & 0.83 \\
1932-1939 & -0.23 & 0.77 & 0.53 \\
1948-1957 & -0.47 & 0.75 & -1.11 \\
AMJJAS & & & \\
1932-1934 & -0.34 & 0.89 & 0.05 \\
1935-1939 & -0.20 & 1.03 & 0.60 \\
1932-1939 & -0.25 & 0.98 & 0.40 \\
1948-1957 & -0.35 & 0.57 & -0.77 \\
\hline
\end{tabular}

All indices are standardized anomalies (zero mean, unit variance). Base period for standardizing is 1900-2009 for PDO and AMO indices. Base period is 1900-2008 for NINO 3.4 index because raw data for 2009 was incomplete. For the 1932-1939 drought, anomalies are also divided into two periods for the earlier (1932-1934) and later (1935-1939) periods of the drought

The expected teleconnections of the Pacific and Atlantic ocean basins to NA climate in the COMPO reanalysis are well resolved, based on correlations between the climate indices and selected dynamical fields for 1909-1958 (Fig. 2). During ONDJFM, the NINO 3.4 index is positively correlated with $200 \mathrm{hPa}$ heights in the tropics, flanked by negative correlations in the midlatitudes, especially over the Pacific and Americas (Fig. 2, top). This represents the zonally and hemispherically symmetric response of the atmosphere to ENSO forcing alluded to in the introduction; the inverse pattern, associated with $\mathrm{La}$ Nina events, is associated with drought over NA. Additionally, positive correlations with pressure vertical velocity at $500 \mathrm{hPa}$ (indicating anomalous subsidence during El Niño events) are seen in expected regions: the Amazon, southern Africa, and the maritime continent (not shown). For the north Atlantic, the dominant season of influence is boreal spring and summer (AMJJAS). The AMO index is negatively correlated with $1,000 \mathrm{hPa}$ heights over the Caribbean and subtropical north Atlantic (Fig. 2, bottom), indicating a weakening of the Azores subtropical high when the north Atlantic is warmer than normal (Sutton and Hodson 2005). The large area of positive correlations over the Pacific sector may indicate some influence from the tropical Pacific, since Atlantic variability, especially in the tropics, is not completely independent from ENSO (Enfield and Mayer 1997). There is also a long band of negative correlations with pressure vertical velocity at 
$850 \mathrm{hPa}$, indicating the northward migration of the Intertropical Convergence Zone in the Atlantic sector when the North Atlantic is warmer than normal (Yoo and Zeng 2009) (not shown). Teleconnections with the PDO during ONDJFM are quite similar to the NINO 3.4 correlations (not shown), again implying that the PDO may be forced wholly or partially from the tropical Pacific. Because of the difficulty in effectively differentiating PDO from ENSO climate impacts in the available datasets, we focus the majority of our analyses and discussion on climate responses to direct ENSO and Atlantic forcing.

Both droughts were predominately warm season droughts, with the largest precipitation deficits and areal extents during AMJJAS (Fig. 3). To determine how well these drought patterns match the idealized pattern that would be expected from a combined Pacific Cold/Atlantic Warm (PCAW) SST pattern, we compare them against an idealized drought pattern calculated from the CRU data using pattern correlations, the product-moment coefficient of linear correlation between variables corresponding to the same location. Pattern correlations are commonly used in verification of forecast fields and can be interpreted identically as a Pearson correlation. The PCAW pattern is calculated by averaging precipitation anomalies for all years, excluding the 1930s and 1950s droughts, with cold Pacific ( -0.5 standard deviation in NINO 3.4) and warm Atlantic $(+0.5$ standard deviation in AMO index) SST conditions (1911, 1918, 1944, 1945, 1976, 1989, 1999, 2000, 2001), maximizing the SST-forced drought signal. Pattern correlations are calculated over the region $20^{\circ} \mathrm{N}-50^{\circ} \mathrm{N}$ and $130^{\circ} \mathrm{W}-$ $80^{\circ} \mathrm{W}$. This area encompasses the primary regions with significant teleconnections to Pacific and Atlantic SSTs, including the Pacific Northwest, the southwest, Mexico, and the southeast. PCAW 9-year composite SST and precipitation anomalies are shown in Figs. 4 and 5.

Comparing Figs. 5 and 7, it is seen that the 1950s drought resembles a classic combined Atlantic and Pacific SST forced drought pattern, with drying extending in a band across the southwestern United States, Mexico, and into the southeastern United States, consistent with the forcing and teleconnections previously shown. The idealized PCAW drought pattern has a much higher pattern
Fig. 2 Teleconnections (Pearson correlations) between climate indices (NINO 3.4 and AMO) and dynamical fields from the early twentieth century reanalysis

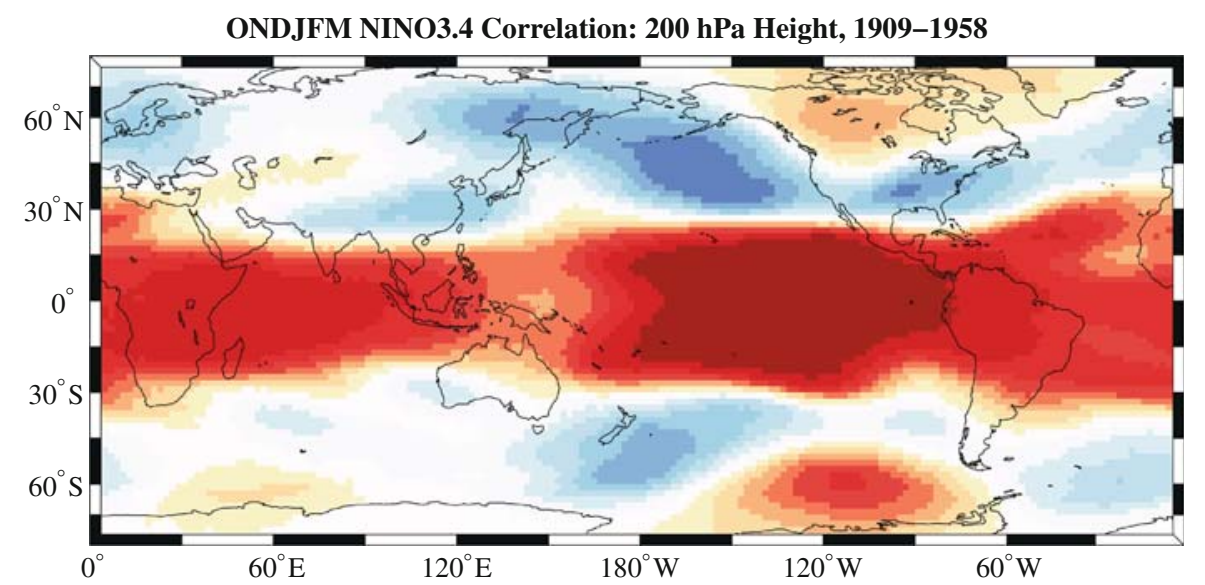

AMJJAS AMO Correlation: 1000 hPa Height, 1909-1958

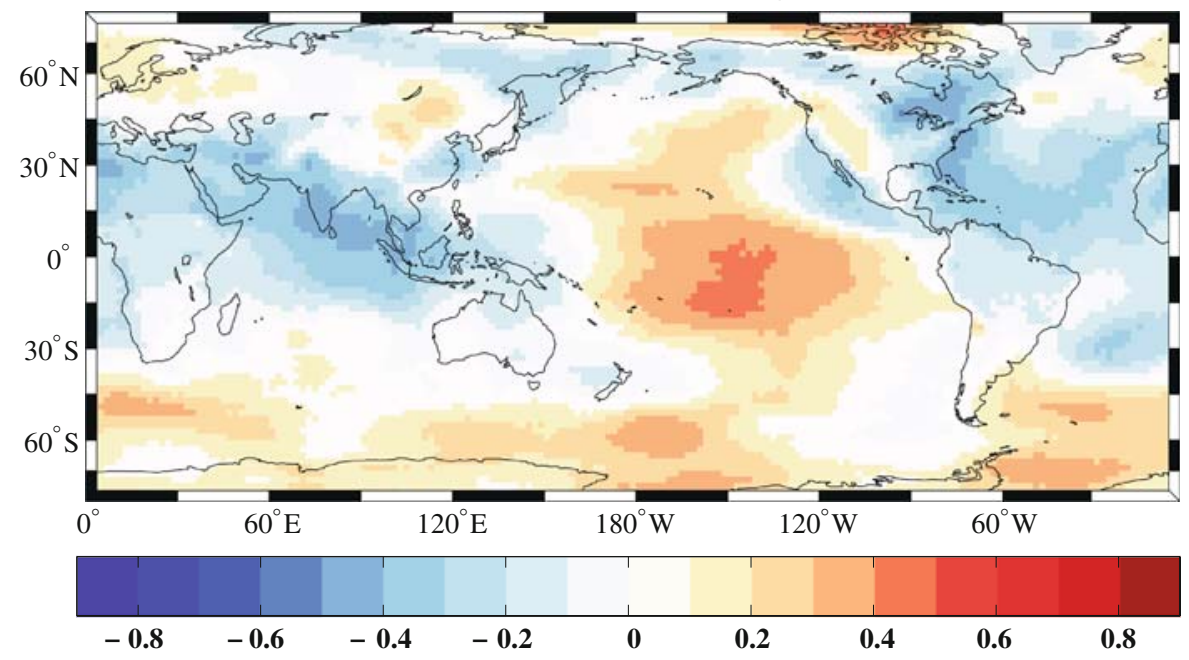



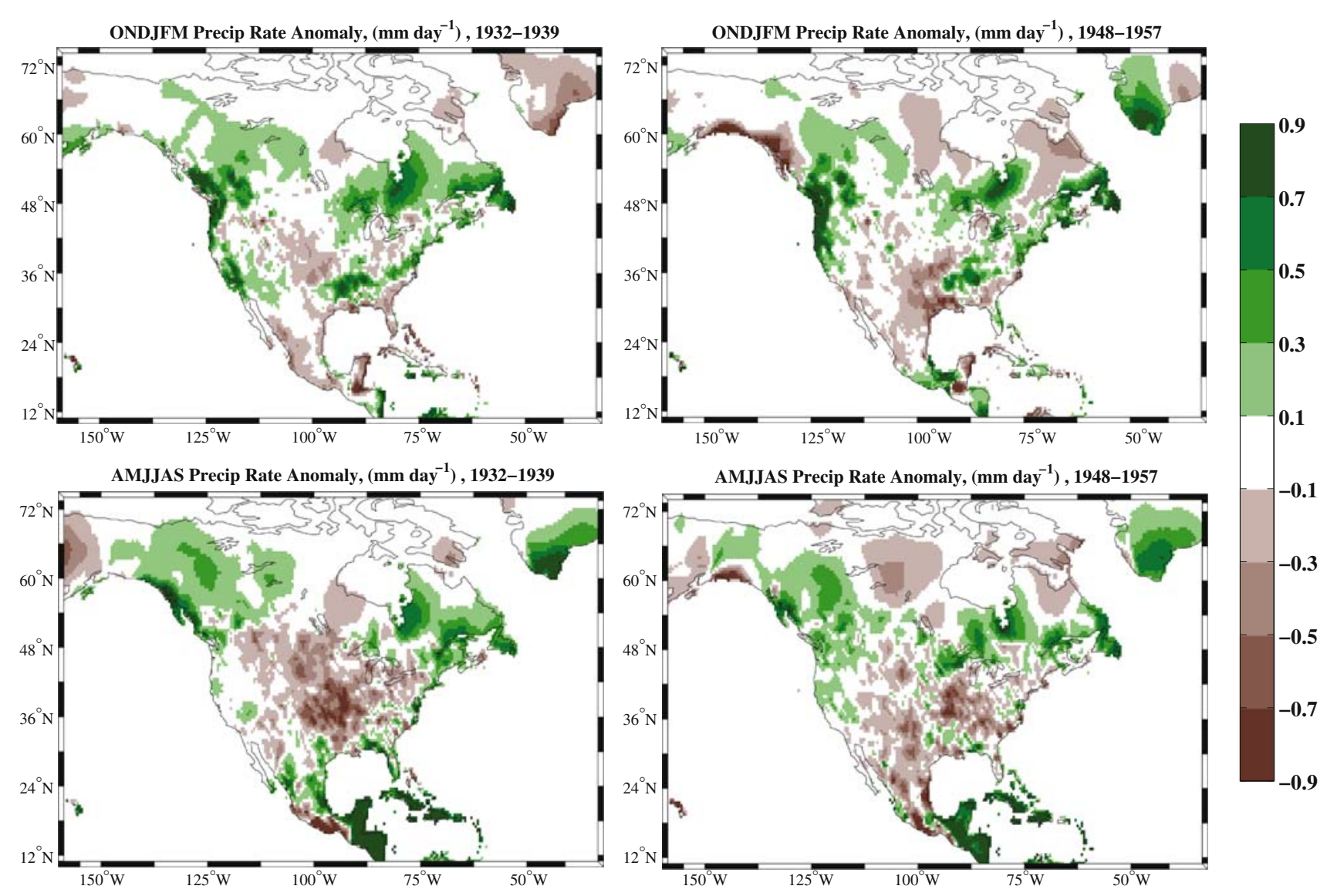

Fig. 3 Precipitation anomalies (mm day ${ }^{-1}$ ) for 1932-1939 and 1948-1957. Anomalies for boreal winter (October-March, ONDJFM) and boreal summer (April-September, AMJJAS) are shown. Data taken from the CRU 2.1 gridded dataset (Mitchell and Jones 2005)

correlation $(r=0.58)$ with the 1950 s drought than the 1930s ( $r=0.24$ ) (Table 2). During the 1930s, the drought is centered predominately over the central Great Plains and has a much larger, continuous extent. The 1930s also show little or no drying in Mexico or the southwestern United States. As noted before, general circulation model experiments using observed SSTs from these periods are typically able to reproduce the pattern and intensity of the 1950s drought, but reproduce the intensity and spatial extent of the 1930s only superficially (e.g., Cook et al. 2009; Schubert et al. 2004a, b; Seager et al. 2008).

\subsection{Model responses to idealized SST forcing}

In order to determine to what extent the circulation anomalies during the 1932-1939 and 1948-1957 droughts fit with expected responses to SST forcing, we first examine results from a series of experiments using the Community Climate Model (CCM) version 3. These simulations are from an inter-model comparison conducted by the U.S. Climate Variability and Predictability working group, investigating the role of SST forcing and landatmosphere feedbacks on drought (Schubert et al. 2009).
In these experiments, the model was forced for fifty years using constant cold Pacific and warm Atlantic SSTs, essentially idealized versions of the boundary conditions present during the COMPO droughts, and compared against a run forced by climatological SSTs. In cases where the dynamics in the COMPO reanalysis match the idealized experiments, we may have some confidence that the drought pattern was SST forced. In cases where the COMPO dynamics and dynamics in the idealized model runs diverge, we search for an alternative explanation.

Height and pressure vertical velocity anomalies in the idealized model experiments are shown in Figs. 6 and 7, respectively. Positive height anomalies extend from the north Pacific and across southwest and southeast NA, essentially the inverse pattern from the NINO 3.4 correlation plot in Fig. 2. There is also a clear wave train emanating from the tropical Pacific during ONDJFM, with negative height anomalies over the subtropical Pacific and northwestern NA and positive anomalies over the north Pacific and Greenland. During AMJJAS, height anomalies at 850 and $500 \mathrm{hPa}$ over the subtropical Atlantic are negative, consistent with AMO correlations from Fig. 2. Pressure vertical velocity anomalies are stronger during 


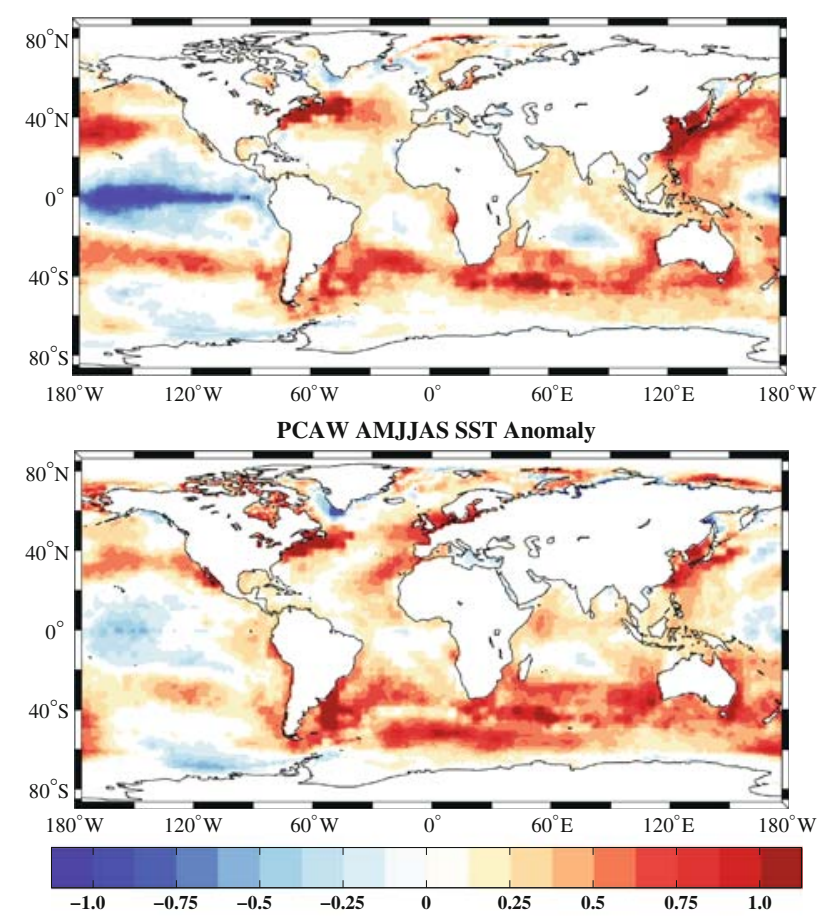

Fig. 4 SST anomalies $\left({ }^{\circ} \mathrm{C}\right)$ from the PCAW composited drought pattern $(1911,1918,1944,1945,1976,1989,1999,2000,2001)$

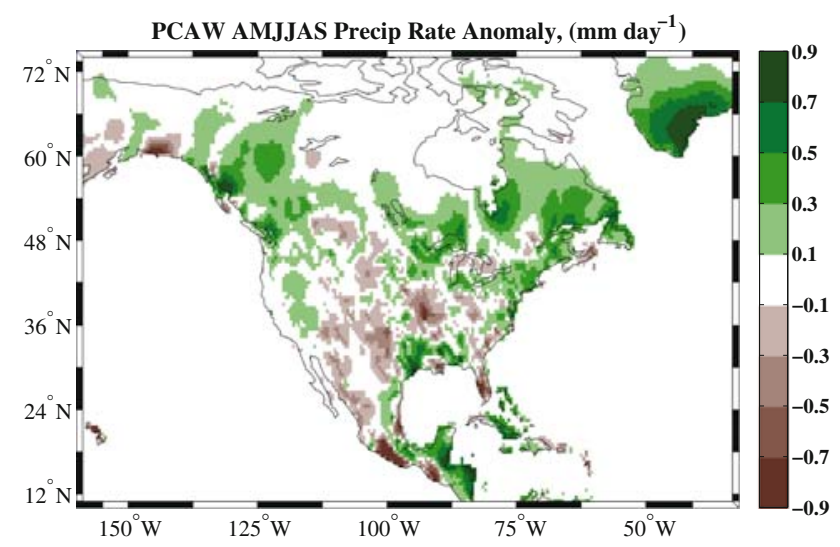

Fig. 5 Precipitation anomalies $\left(\mathrm{mm} \mathrm{day}^{-1}\right)$ from the PCAW composited drought pattern $(1911,1918,1944,1945,1976,1989,1999$, 2000, 2001)

Table 2 Pattern correlations between observed (CRU) and modeled (SST-ONLY, SST + LAND) drought patterns over the region $20^{\circ} \mathrm{N}-$ $50^{\circ} \mathrm{N}$ and $130^{\circ} \mathrm{W}-80^{\circ} \mathrm{W}$

\begin{tabular}{llll}
\hline & CRU (PCAW) & SST-ONLY & SST + LAND \\
\hline CRU (1932-1939) & 0.24 & 0.21 & 0.41 \\
CRU (1948-1957) & 0.58 & 0.23 & 0.26 \\
CRU (PCAW) & N/A & 0.06 & 0.07 \\
\hline
\end{tabular}

PCAW refers to composited drought patterns from years with cold Pacific and warm Atlantic SSTs (1911, 1918, 1944, 1945, 1976, 1989, 1999, 2000, 2001)
ONDJFM, with anomalous subsidence in the Pacific and southwest/southeast NA flanking a band of anomalous uplift; though diminished, the subsidence over southwest/ southeast NA continues into AMJJAS.

\subsection{Observed droughts, height anomalies $(200,500,850 \mathrm{hPa})$}

In the COMPO reanalysis during ONDJFM (Fig. 8), both droughts have positive height anomalies in the north Pacific, especially at 200 and $500 \mathrm{hPa}$. For 1948-1957, this is indicative of a wave train emanating from the tropical Pacific, with positive anomalies in the north Pacific flanked by negative height anomalies over northwest NA and the subtropical Pacific. The wave pattern for 1948-1957 is shifted southwest relative to the idealized anomalies in Fig. 6; positive heights are over northeast Canada instead of Greenland, and the negative anomalies in northwestern NA extend too far to the southeast. Still, the 1948-1957 anomaly pattern is largely consistent with the idealized response. Circulation anomalies during 1932-1939 diverge much more strongly from the idealized case in Fig. 6; positive height anomalies extend across NA zonally from the North Pacific to the North Atlantic basin. Both droughts lack the expected high pressure over southeast NA during ONDJFM, although 1948-1957 does show positive heights over the west and southwest at 200 and $500 \mathrm{hPa}$.

In the warm season, AMJJAS (Fig. 9), the most notable deviation from the expected response is a strong ridge of high pressure at 200 and $500 \mathrm{hPa}$ centered over central NA during 1932-1939. This feature is remarkably consistent with an independent analysis of upper air observations during the 1930s (Brönnimann et al. 2009), a study that also identified an upper level ridge over NA during this drought. For 1932-1939, there is also a widespread anticyclonic anomaly over western NA at $850 \mathrm{hPa}$ which, when combined with the negative height anomalies over the southeast, acts counter to the climatological flow from the Gulf of Mexico and into the continent (see Sect. 3.5). Both droughts show the negative height anomalies over the tropical/subtropical north Atlantic during AMJJAS; these reflect a typical response to warm Atlantic SSTs (Fig. 6) (Kushnir et al. 2010).

\subsection{Observed droughts, pressure vertical velocity (500 hPa)}

Pressure vertical velocity anomalies at $500 \mathrm{hPa}$ for both droughts (Fig. 10) correspond closely to the precipitation anomalies (Fig. 3) from the CRU data. For 1948-1957, the anomalous subsidence is focused over southwest and southeast NA, a typical response to the combination of $\mathrm{La}$ Nina forcing and a warm subtropical Atlantic. The 

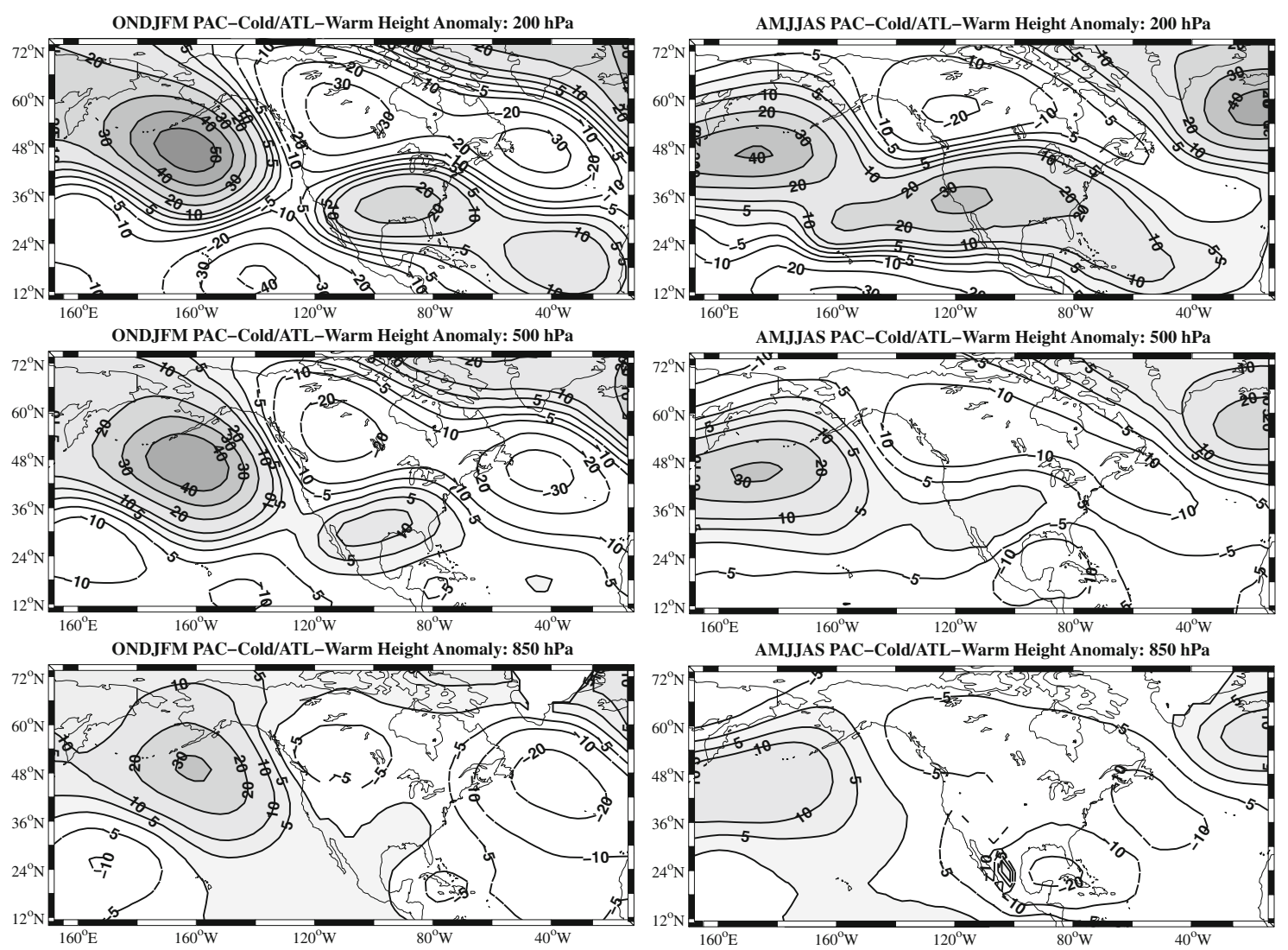

Fig. 6 Height anomalies (m) from CCM model experiments forced with an idealized cold Pacific and warm Atlantic SSTs. Anomalies are relative to a 50-year run forced by climatological SSTs

subsidence during the 1950s persists through both seasons, remaining in roughly the same location but intensifying during AMJJAS. For 1932-1939, the anomalous subsidence also closely overlaps the precipitation anomalies, but is centered farther north over the central Great Plains. The 1930s anomalies also have a much more widespread and continuous extent, spreading out to cover much of the continental United States. Notably, subsidence anomalies in the southwest and southeast are weaker for the 1930s compared to the $1950 \mathrm{~s}$, supporting the notion that SST forcing only weakly contributed to the spatial pattern and intensity of the Dust Bowl drought. As an aside, we note the close association between the subsidence and precipitation anomalies helps to increase our confidence in the validity of the COMPO reanalysis, since these two products use completely independent underlying datasets.

\subsection{Observed droughts, Great Plains low-level jet}

An important feature of the warm season climate over the Great Plains is the Great Plains low-level jet (GPLLJ), characterized by a maximum in low level wind speeds, with the jet core extending from the Gulf of Mexico into the central Great Plains (Higgins et al. 1997; Weaver and
Nigam 2008). The GPLLJ is strongest during May-June, although it is active throughout the warm season, and is an important mechanism for moisture transport from the Gulf into the continental interior (Weaver and Nigam 2008). The GPLLJ appears to have the strongest impact on precipitation during late summer, July-September (Weaver et al. 2009). Variations in the strength of the GPLLJ have been linked to severe droughts and floods in the Plains in previous studies (Arritt et al. 1997; Mo et al. 1997).

From the COMPO reanalysis, we calculated a GPLLJ index for AMJJAS by averaging meridional wind speed below $900 \mathrm{hPa}$ from $25^{\circ} \mathrm{N}-35^{\circ} \mathrm{N}$ and $102^{\circ} \mathrm{W}-97^{\circ} \mathrm{W}$ (after Weaver and Nigam 2008), with anomalies calculated relative to 1921-1929 (our common baseline period). The reanalysis shows marked variability in the strength of the jet (Fig. 11), with extended periods of low wind speeds during the 1930s (1932-1936) and 1940s (1942-1945). This is in sharp contrast to the 1948-1957 drought, when the jet is close to average strength or weakly enhanced. The weakening of the jet for the 1930s drought and the impact of the Atlantic on moisture fluxes from the Gulf of Mexico into the Great Plains has been noted previously (Brönnimann et al. 2009; Schubert et al. 2004b). Our GPLLJ index was not significantly correlated to either Atlantic or Pacific 


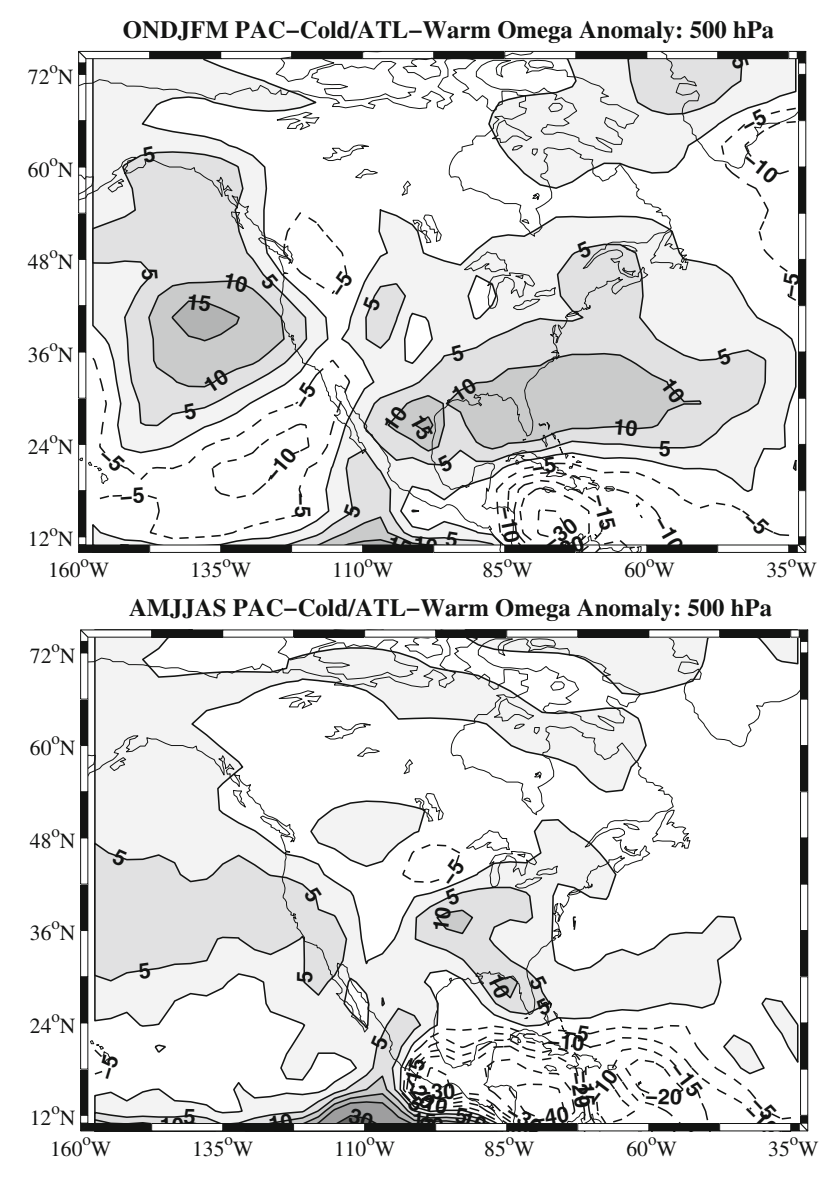

Fig. 7 Pressure vertical velocity anomalies $\left(\mathrm{Pa} \mathrm{s}^{-1} \times 1,000\right)$ from CCM model experiments forced with an idealized cold Pacific and warm Atlantic SSTs. Anomalies are relative to a 50-year run forced by climatological SSTs

SSTs, which is not especially surprising because of the complex and seasonally dependent nature of correlations between the GPLLJ and SSTs (Weaver et al. 2009). Instead, the variability in the jet in the COMPO reanalysis appears to be tightly linked to dynamics over NA, as correlations with the geopotential height fields show (Fig. 12, left and middle panels). The jet weakens when high pressure dominates at high levels over central NA and at low levels over the west, and is associated with reduced atmospheric moisture in the central Great Plains region (Fig. 12, right panel). The relationship between the GPLLJ and circulation in our analyses is largely consistent with other studies (Weaver et al. 2009).

As noted previously (Fig. 9), the 1932-1939 drought is dominated during the summer season by an upper level ridge and low level anticyclonic anomaly over western NA, features absent during the 1948-1957 drought. This appears to be the dynamical explanation for the weakening of the jet during the 1930s. The importance of the GPLLJ during the 1932-1939 drought can also be seen in the specific humidity anomalies (not shown). During the
1932-1939 drought there are strong reductions in atmospheric moisture over the central Great Plains; for 19481957 moisture reductions are confined predominately to the southwest and southeast regions, where SST forcing dominates.

\subsection{Model comparison}

Precipitation anomalies from a series of model experiments using GISS ModelE are shown in Fig. 13. In the left panel are ensemble mean anomalies from a 1932-1939 simulation forced by observed SSTs, with default land surface characteristics and no dust aerosols (SST-ONLY). On the right are anomalies from an ensemble for the same period, forced by observed SSTs, land degradation in the form of crop areas converted to bare soil, and radiatively active dust aerosols originating from a Great Plains dust source (SST + LAND). In the SST-ONLY case, the model simulates a drought that closely resembles a typical La Nina type drought, with moderate drying in the southwest and southeast. When land degradation factors are included (SST + LAND), the drought intensifies and expands northward into the Great Plains. Pattern correlations of the modeled drought patterns against the observed precipitation pattern during the 1930s (Table 2) shows a large improvement in the simulated drought pattern when land degradation effects are included ( $r=0.21$ for SST-ONLY; $r=0.41$ for SST + LAND). While results from the GISS model experiments are not directly comparable to either the 1950s drought or the idealized (PCAW) pattern (due to different SST boundary conditions), these comparisons can still be informative. For example, addition of land degradation to the model (SST + LAND) does not improve the pattern correlation between the modeled 1930s drought and the observed 1950s and PCAW droughts. This fits well with existing evidence that these drought patterns are predominately tied to SST forcing, rather than forcing or feedbacks from the land surface.

The additional drying in SST + LAND comes primarily from the dust aerosols, which reduce net radiation at the surface and the top of the atmosphere, primarily through enhanced reflection of shortwave radiation. The net radiation reductions drive a feedback similar to the 'Charney' mechanism (Charney 1975), where reduced energy inputs to the atmospheric column are compensated by subsidence and adiabatic heating in order to restore thermodynamic equilibrium. The anomalous subsidence, in turn, reduces precipitation primarily by suppressing convection (Cook et al. 2009). Vegetation losses act as a secondary amplifier by limiting evapotranspiration and moisture supply to the atmosphere, and lead to warming of the surface throughout the Great Plains as the Bowen ratio shifts from latent to sensible heating. Even with the improved precipitation in 

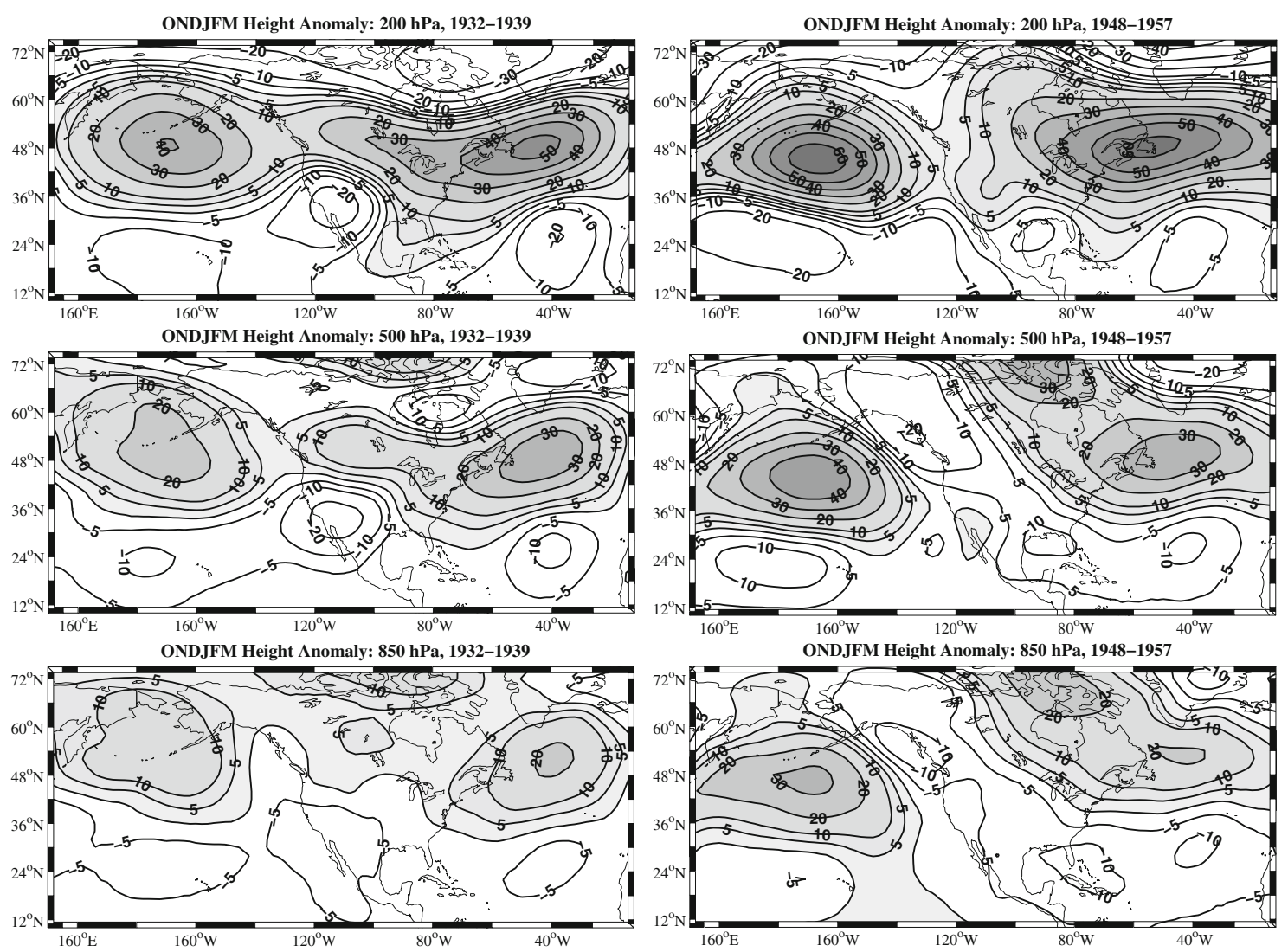

Fig. 8 ONDJFM Height anomalies (m) at 200, 500, and $850 \mathrm{hPa}$ for 1932-1939 and 1948-1957. Anomalies are calculated relative to mean conditions for 1921-1929

SST + LAND, there is still too much drying in Mexico and the southwest, but this may reflect either deficiencies in the GISS model simulation of ENSO teleconnections or other factors not accounted for in the model simulations. At the time when Cook et al. (2009) was published, large scale dynamical datasets such as the COMPO reanalysis were unavailable for comparison against the model simulations, and validation efforts were limited to comparisons against temperature and precipitation. With the COMPO reanalysis now available, we can revisit these model experiments with the purpose of determining if the dust aerosols and vegetation reductions modify the model dynamics in directions consistent with the COMPO reanalysis.

The circulation response to land degradation in the model is strongest during late summer and early autumn (August-October, ASO). In the left column of Fig. 14 are model anomalies for precipitation, $850 \mathrm{hPa}$ geopotential height, and $500 \mathrm{hPa}$ pressure vertical velocity for the SST + LAND experiments. These are relative to a 19211929 model control run with SST forcing only, and are analogous to the anomaly plots we have seen previously for the COMPO reanalysis. In the right column of Fig. 14 are differences between the two 1932-1939 simulations (SST + LAND minus SST-ONLY). These represent the added effect of the land degradation (devegetation and dust aerosols) beyond the SST forcing. As seen in the precipitation anomalies, land degradation shifts the drought northward in the model, such that the drying is now focused over the northern and central Great Plains (Fig. 14, top panels). At low levels, a high pressure develops over central NA (Fig. 14, middle panels). This is especially clear in the difference plot on the right (SST + LAND minus SST-ONLY), where the addition of dust aerosols and land cover changes enhances the anticyclonic anomaly over western NA at $850 \mathrm{hPa}$. The anticyclonic anomaly acts counter to the climatological flow, weakening the model GPLLJ slightly in the SST + LAND experiment. For the SST-ONLY experiments, the 1932-1939 GPLLJ anomaly (relative to the model mean for 1921-1929) is slightly positive $\left(+0.145 \mathrm{~m} \mathrm{~s}^{-1}\right)$; in SST + LAND, the model simulates a slight weakening of the jet $\left(-0.152 \mathrm{~m} \mathrm{~s}^{-1}\right)$. These anomalies represent departures of about half an interannual standard deviation for the 19211929 base period $\left(0.364 \mathrm{~m} \mathrm{~s}^{-1}\right)$, but are relatively small compared to the observed anomalies (Fig. 11). In general, 

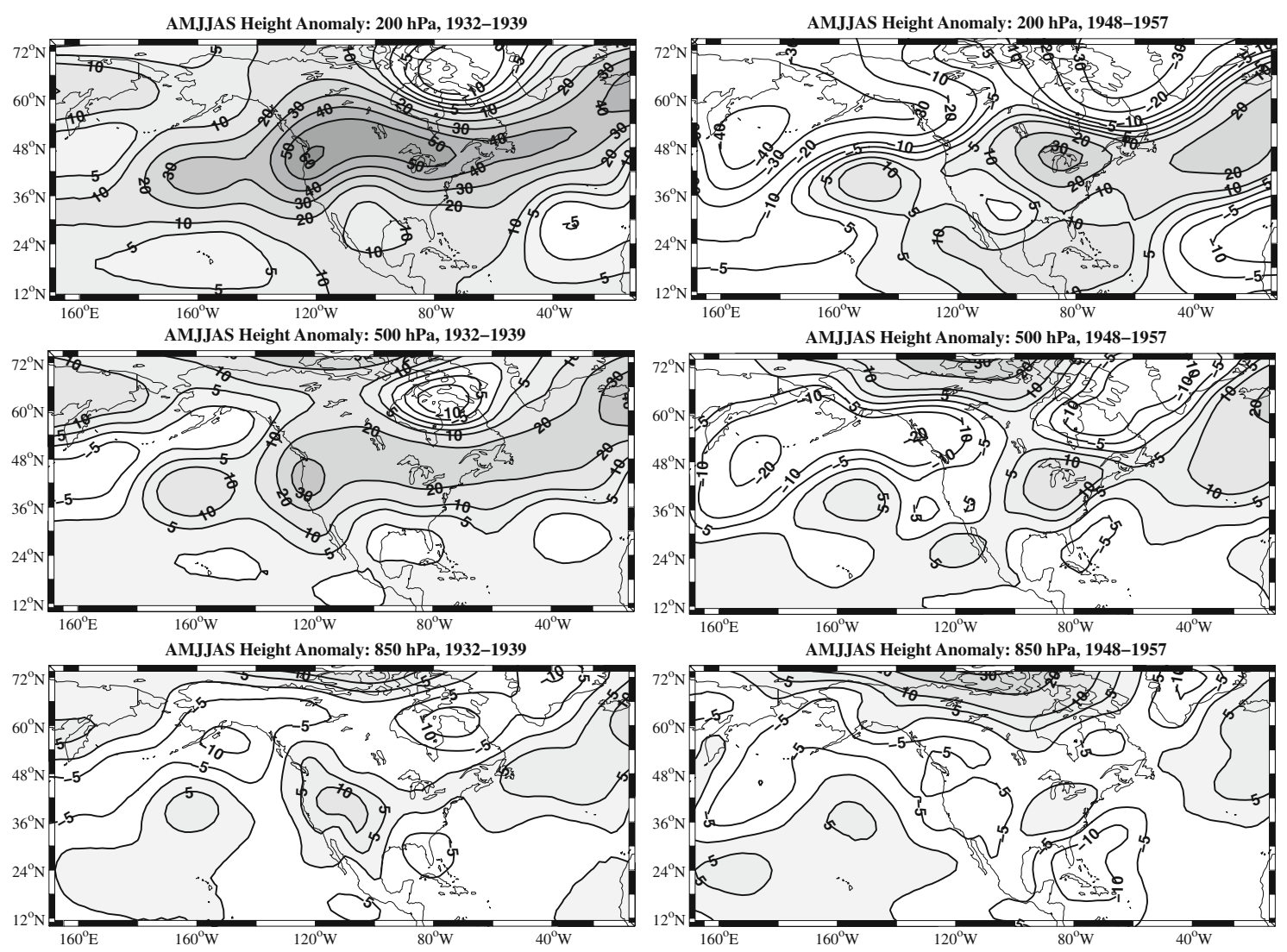

Fig. 9 AMJJAS Height anomalies (m) at 200, 500, and $850 \mathrm{hPa}$ for 1932-1939 and 1948-1957. Anomalies are calculated relative to mean conditions for 1921-1929

the GISS model adequately reproduces the climatological magnitude of the GPLLJ, but has much diminished interannual variability compared to observations.

The most important response in the model is the intensification and spreading of the anomalous subsidence (Fig. 14, bottom panels). The subsidence anomalies match well with the precipitation anomalies in the model, and are the primary driver behind the drying (via the 'Charney' mechanism, mentioned previously). The fact that the model can largely reproduce the drought without major changes in the GPLLJ suggests that the jet may be a secondary actor and may be most important for reinforcing precipitation anomalies that are controlled primarily by vertical motions. Dust aerosol effects in the GISS model are confined primarily to the lower portion of the atmosphere, below 500 $\mathrm{hPa}$, and do not act to enhance the upper level ridging observed in the COMPO reanalysis.

\section{Discussion and conclusions}

Dynamical studies of persistent drought events over NA (and the globe) have been limited by the availability of data (e.g., winds, pressure fields, etc). Over the last 60 years, for which comprehensive circulation data are readily available, there have only been two persistent North American droughts, 1948-1957 and 1998-2004. This has forced the drought research community to rely primarily on GCM experiments forced by observed SSTs to examine the underlying dynamics and to test our understanding of persistent NA hydroclimatic variability, especially for droughts prior to the 1948-1957 event (e.g., Herweijer et al. 2006, 2007; Nigam and Ruiz-Barradas 2006; Seager et al. 2005b; Seager 2007). While these modeling studies have been largely successful for almost all NA droughts, many models have difficulty simulating the Dust Bowl temperature and precipitation anomalies using SST forcing alone. This is not especially surprising, given that the Dust Bowl anomalies diverge widely from the typical pattern observed during other instrumental period droughts. Whether this discrepancy with observations is the result of missing physical mechanisms (such as land degradation considered here), the superposition of unforced variance on top of the response to SST anomalies, or a consequence of model deficiencies has been difficult to investigate given the limited data available during the Dust Bowl. To help fill this research gap, we have used a new reanalysis product, combined with recent GCM experiments, to compare 

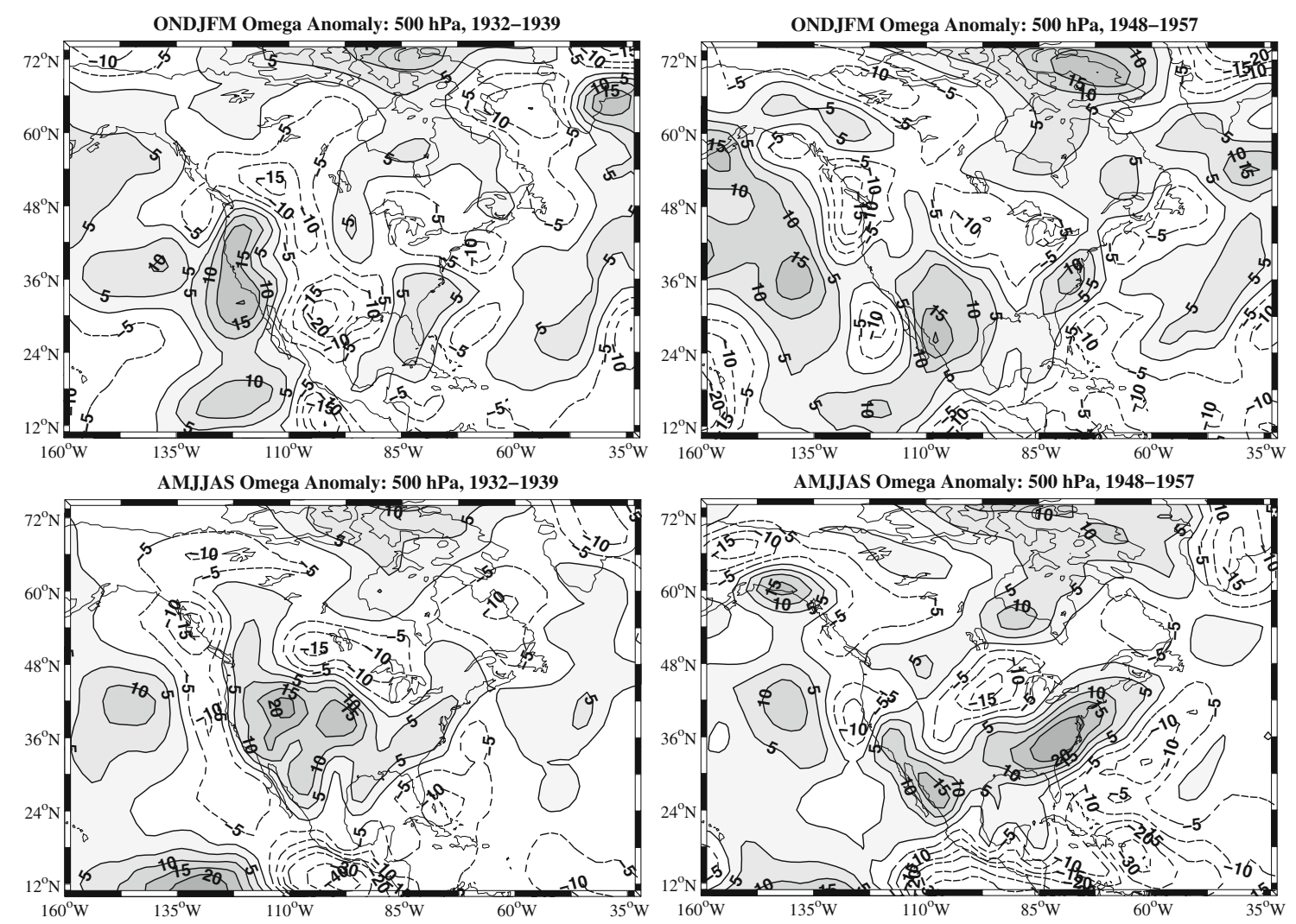

Fig. 10 ONDJFM and AMJJAS pressure vertical velocity anomalies $\left(\mathrm{Pa} \mathrm{s}^{-1} \times 1,000\right)$ at $500 \mathrm{hPa}$ for 1932-1939 and 1948-1957. Anomalies are calculated relative to mean conditions for 1921-1929

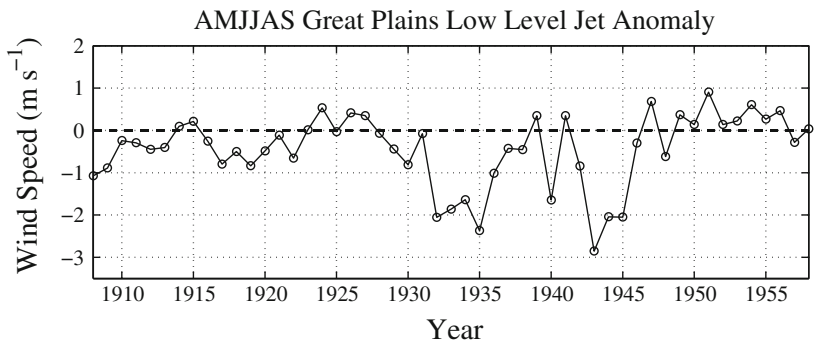

Fig. 11 Great Plains low-level jet index $\left(\mathrm{m} \mathrm{s}^{-1}\right)$ calculated from the COMPO reanalysis, averaged over AMJJAS. Index values are expressed as anomalies, relative to the mean for 1921-1929 circulation features during the 1930s Dust Bowl and the 1950s drought and offer support for a plausible mechanism to explain the differences:

- To varying extents, circulation anomalies (especially in the tropical/subtropical Atlantic and north Pacific ocean basins) during the 1932-1939 and 1948-1957 droughts are consistent with forcing from a combined cold eastern tropical Pacific/warm Atlantic SST pattern.

- Observed subsidence anomalies match well with precipitation anomalies in both droughts, a noteworthy correspondence given that the two underlying data
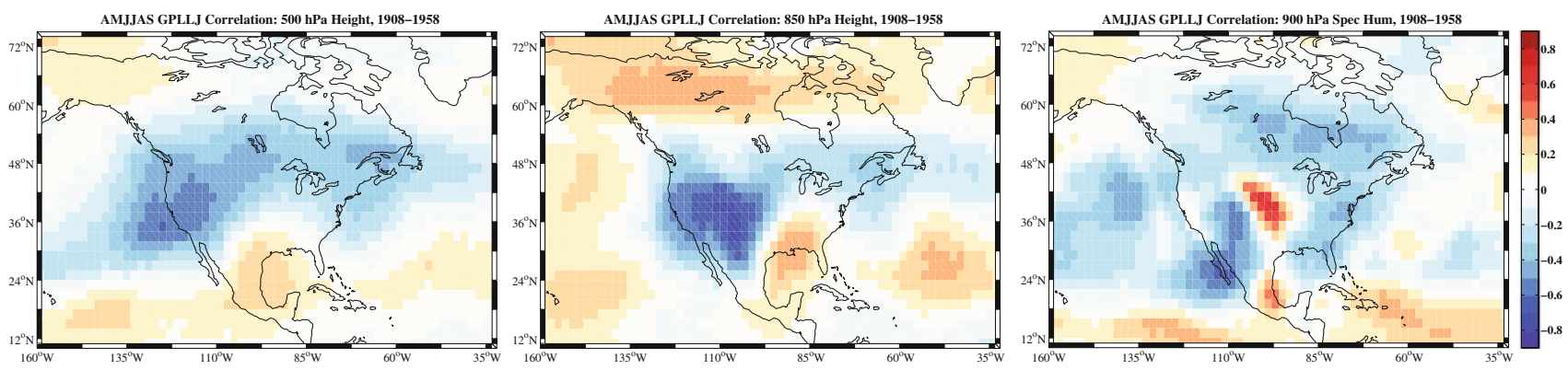

Fig. 12 Pearson correlation between Great Plains low-level jet index (Fig. 11) and $500 \mathrm{hPa}$ height, $850 \mathrm{hPa}$ height, and $900 \mathrm{hPa}$ specific humidity for AMJJAS 


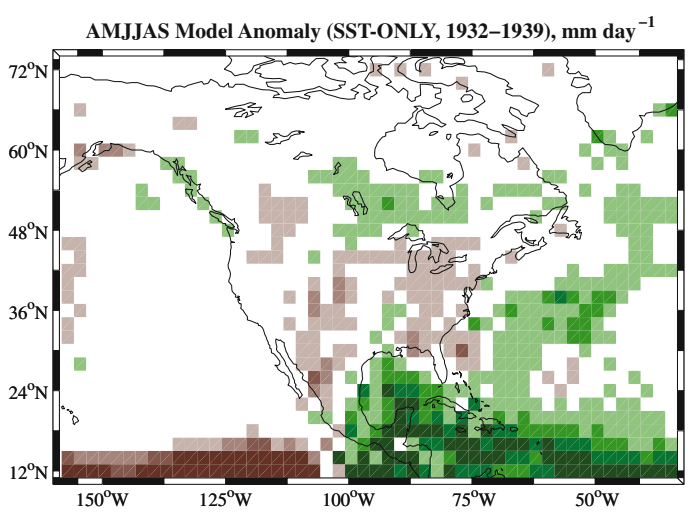

Fig. 13 Ensemble mean AMJJAS precipitation anomalies (mm day $^{-1}$ ) for two Dust Bowl drought simulations using GISS ModelE. SST-ONLY refers to simulations forced by observed SSTs;

products are based on independent observations. The precipitation and subsidence anomalies during the 1950s occur predominately over the southwest, Mexico, and the southeast. For the 1930s, both precipitation and subsidence anomalies are centered over the central Great Plains, inconsistent with what would be expected from SST forcing alone. The idealized SST forced drought pattern (PCAW) correlates much more strongly with the 1950s drought $(r=0.58)$ than with the 1930 s drought $(r=0.24)$.

- The 1930s drought is dominated by an upper level $(200 \mathrm{hPa})$ ridge and low level $(850 \mathrm{hPa})$ anticyclonic anomaly over western NA, circulation features that appear to drive a sharp reduction in the strength of the GPLLJ. These patterns, and the weakening of the jet, are absent during 1948-1957.

- Model simulations with dust aerosols and land degradation factors, in addition to SSTs, are able to improve the model simulation of some of the circulation anomalies, including the enhanced subsidence over the Great Plains and the low-level anticyclonic anomaly over western NA. However, the model is unable to reproduce the $200 \mathrm{hPa}$ ridging and simulates a relatively minor weakening of the GPLLJ, even when the land degradation factors are included.

Remaining differences between our simulations and the reanalysis could be related to either uncertainties in our estimation of the boundary forcing (e.g., magnitude of dust aerosol loading), other physical processes not represented in the model, or deficiencies in the model itself. Alternative explanations to explain the anomalous nature of the Dust Bowl drought have also been proffered in the literature. It has been speculated that the warm Atlantic may have been enough to extend the drought beyond the initial ENSO forcing, and that any differences between the Dust Bowl

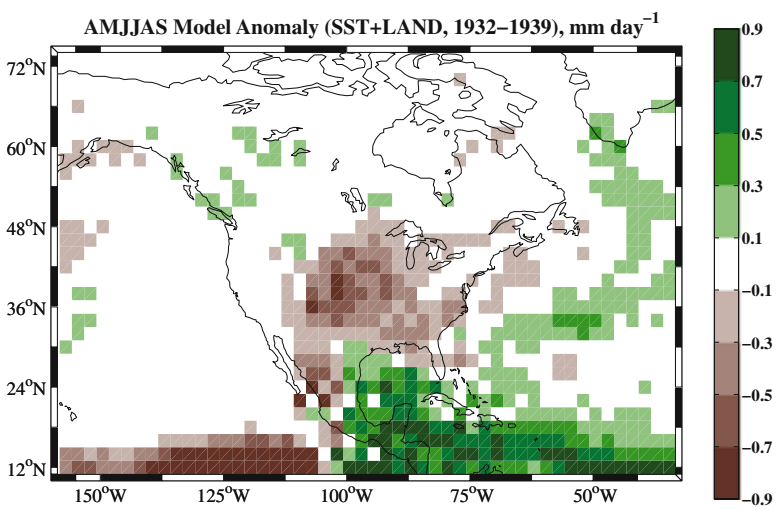

SST + LAND includes observed SSTs and land degradation effects (crop failure and dust aerosols)

and other droughts, such as the 1948-1957 drought, can be attributed to internal, unforced variability (Hoerling et al. 2009; Schubert et al. 2004a, b). Regarding the Atlantic influence, most model simulations of the Dust Bowl drought do include forcing from observed Atlantic SSTs (Hoerling et al. 2009; Schubert et al. 2004a, b; Seager et al. 2008), and recent work suggests that circulation responses to the Atlantic forcing are accurately represented in the models (Kushnir et al. 2010; Schubert et al. 2009). Even with presumably accurate representations of Atlantic and Pacific SST forcing, however, most models are only able to partially reproduce the pattern, intensity, and location of the Dust Bowl precipitation anomalies (Hoerling et al. 2009; Schubert et al. 2004a, b; Seager et al. 2008). In some multi-member ensemble simulations, precipitation anomalies in certain ensemble members do bear a remarkable resemblance to the observed precipitation anomalies (Schubert et al. 2004a, b; Seager et al. 2008), supporting the claim that natural variability played a role. To our knowledge, however, even these SST forced simulations are unable to reproduce the continental scale warming associated with the Dust Bowl drought. This warming can be reproduced in model simulations when land surface degradation factors are included (Cook et al. 2009). Additionally, if natural variability was an important factor, one would expect to find Dust Bowl analogues in the extensive, 2000 year long paleo-record of drought for North America (Cook et al. 2004). Past droughts that bear a superficial resemblance to the Dust Bowl can be be identified; they are quite rare, however, and none fully capture the combined magnitude, duration, and geographical extent of the Dust Bowl (Fye et al. 2003; Seager et al. 2008). Seager et al. (2008), for example, found only three potential analogues, and even in those cases the pattern correlation match between those droughts and the Dust 

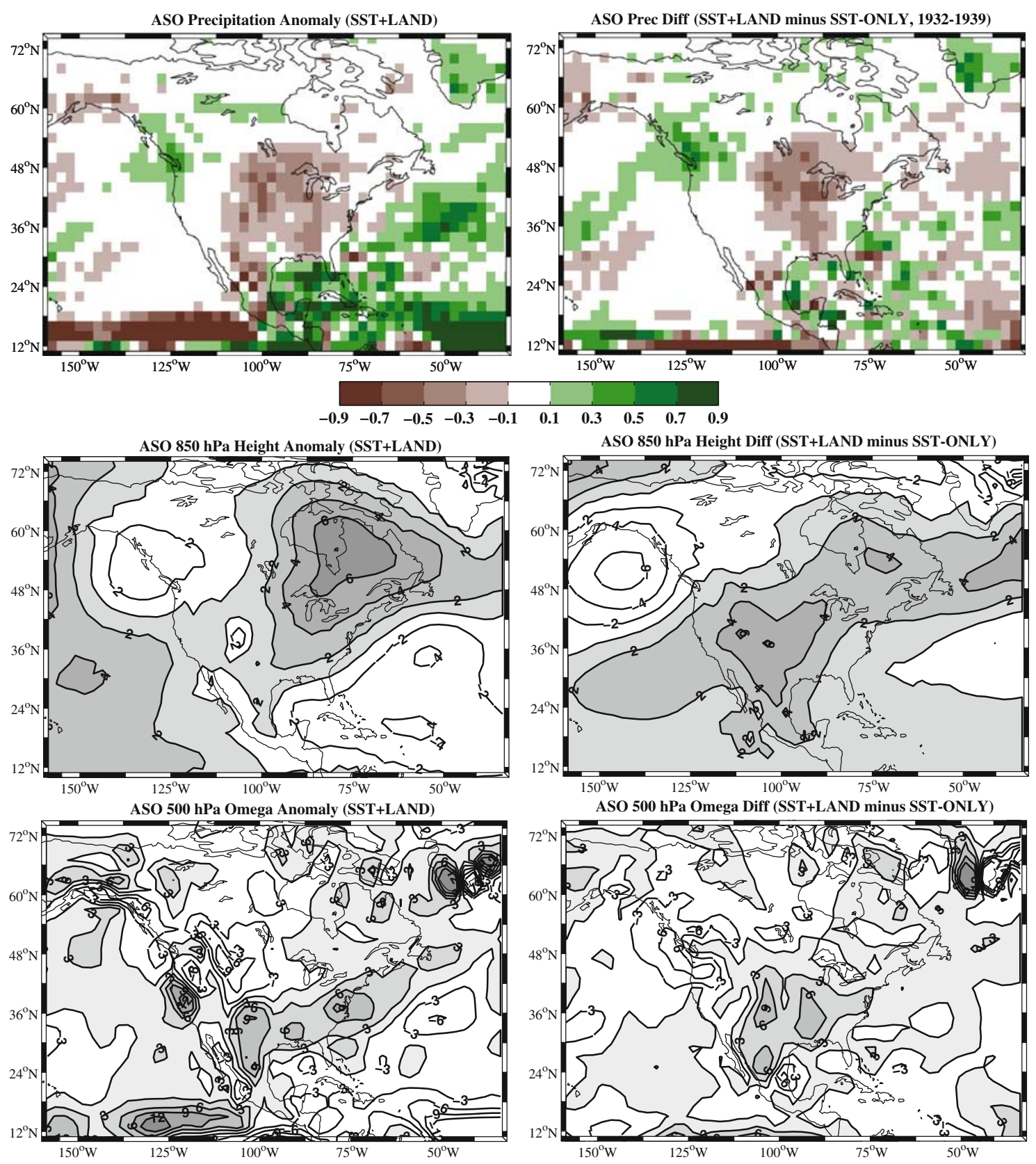

Fig. 14 Anomalies (SST + LAND relative to a 1921-1929 SST forced run) and differences (SST + LAND minus SST-ONLY, 19321939) in $850 \mathrm{hPa}$ heights (m), $500 \mathrm{hPa}$ pressure vertical velocity

Bowl was only $0.40-0.50$. This suggests that natural variability is insufficient, by itself, to explain the Dust Bowl drought.

Natural variability and the land degradation effects may have both significantly contributed to the unique nature of the Dust Bowl, and this has been suggested by others (Brönnimann et al. 2009; Hoerling et al. 2009). The question remains open, but results and conclusions from the modeling studies with dust aerosols and land cover changes (Cook et al. 2008, 2009) are consistent with the

$\left(\mathrm{Pa} \mathrm{s}^{-1} \times 1,000\right)$, and precipitation $\left(\mathrm{mm} \mathrm{day}^{-1}\right)$ from GISS model simulations (SST + LAND minus SST-ONLY)

COMPO reanalysis. Clarification of the importance of land degradation relative to natural variability during the Dust Bowl will require further model experiments, including better estimation of the dust aerosol loading and surface changes and inclusion of these effects in other GCMs.

Acknowledgments Twentieth century reanalysis data provided by the NOAA/OAR/ESRL PSD, Boulder, Colorado, USA, from their Web site at http://www.cdc.noaa.gov. This project received support from the Climate Dynamics Program of the National Science Foundation under ATM-06-20066. The authors also wish to thank two 
anonymous reviewers who greatly improved the quality of this manuscript. Lamont contribution number 7341.

\section{References}

Arritt R, Rink T, Segal M, Todey D, Clark C, Mitchell M, Labas K, (1997) The Great Plains low-level jet during the warm season of 1993. Mon Weather Rev 125:2176-2192

Brönnimann S, Stickler A, Griesser T, Ewen T, Grant A, Fischer A, Schraner M, Peter T, Rozanov E, Ross T (2009) Exceptional atmospheric circulation during the "Dust Bowl". Geophys Res Lett 36:L08802

Charney J (1975) Dynamics of deserts and drought in the Sahel. Q J R Meteorol Soc 101:193-202

Compo G, Whitaker J, Sardeshmukh P (2006) Feasibility of a 100year reanalysis using only surface pressure data. Bull Am Meteorol Soc 87:175-190

Cook B, Miller R, Seager R (2008) Dust and sea surface temperature forcing of the 1930s "Dust Bowl" drought. Geophys Res Lett 35:L08710

Cook B, Miller R, Seager R (2009) Amplification of the North American "Dust Bowl" drought through human-induced land degradation. Proc Natl Acad Sci 106:4997

Cook E, Woodhouse C, Eakin C, Meko D, Stahle D (2004) Long-term aridity changes in the Western United States. Science 306:10151018

Enfield D, Mayer D (1997) Tropical Atlantic sea surface temperature variability and its relation to El Niño-Southern Oscillation. J Geophys Res 102:929-945

Enfield D, Mestas-Nunez A, Trimble P (2001) The Atlantic Multidecadal Oscillation and its relationship to rainfall and river flows in the Continental US. Geophys Res Lett 28:2077-2080

Fye F, Stahle D, Cook E (2003) Paleoclimatic analogs to twentiethcentury moisture regimes across the United States. Bull Am Meteorol Soc 84:901-909

Griesser T, Bronnimann S, Grant A, Ewen T, Stickler A, Zurich E (2008) Reconstruction of upper-level temperature and geopotential height fields for the northern extratropics back to 1920 . Technical report, ETH Zurich. http://www.iac.ethz.ch/en/ climatology/reconstructions.html

Hansen J, Sato M, Ruedy R, Kharecha, Lacis A, Miller R, Nazarenko L, Lo K, Schmidt G, Russell G, et al (2007) Climate simulations for 1880-2003 with GISS modelE. Clim Dyn 29:661-696

Hansen Z, Libecap G (2004) Small farms, externalities, and the Dust Bowl of the 1930s. J Political Econ 112:665-694

Herweijer C, Seager R, Cook E (2006) North American droughts of the mid to late nineteenth century: a history, simulation and implication for Mediaeval drought. Holocene 16:159

Herweijer C, Seager R, Cook E, Emile-Geay J (2007) North American droughts of the last Millennium from a gridded network of tree-ring data. J Clim 20:1353-1376

Higgins R, Yao Y, Yarosh E, Janowiak J, Mo K (1997) Influence of the Great Plains low-level jet on summertime precipitation and moisture transport over the central United States. J Clim 10:481507

Hoerling M, Kumar A (2003) The perfect ocean for drought. Science 299:691

Hoerling M, Quan X, Eischeid J, (2009) Distinct causes for two principal US droughts of the 20th century. Geophys Res Lett 36:L19708

Kalnay E, Kanamitsu M, Kistler R, Collins W, Deaven D, Gandin L, Iredell M, Saha S, White G, Woollen J, et al (1996) The NCEP/ NCAR 40-year reanalysis project. Bull Am Meteorol Soc 77:437-471
Keenlyside N, Latif M, Jungclaus J, Kornblueh L, Roeckner E (2008) Advancing decadal-scale climate prediction in the North Atlantic sector. Nature 453:84-88

Koven C (2006) On the sources, composition, and climatic effects of mineral dust in the atmosphere. Ph.D. thesis, University of California, Berkeley.

Kushnir Y, Seager R, Ting M, Naik N, Nakamura J (2010) Mechanisms of Tropical Atlantic SST influence on North American hydroclimate variability. J Clim

Mantua N, Hare S (2002) The Pacific decadal oscillation. J Oceanogr $58: 35-44$

Mantua N, Hare S, Zhang Y, Wallace J, Francis R (1997) A Pacific interdecadal climate oscillation with impacts on Salmon production. Bull Am Meteorol Soc 78:1069-1079

McCabe G, Betancourt J, Gray S, Palecki M, Hidalgo H (2008) Associations of multi-decadal sea-surface temperature variability with US drought. Quat Int 188:31-40

McCabe G, Palecki M, Betancourt J (2004) Pacific and Atlantic Ocean influences on multidecadal drought frequency in the United States. Proc Natl Acad Sci 101:4136-4141

Miller R, Cakmur R, Perlwitz J, Geogdzhayev I, Ginoux P, Kohfeld K, Koch D, Prigent C, Ruedy R, Schmidt G, et al (2006) Mineral dust aerosols in the NASA Goddard Institute for Space Sciences ModelE atmospheric general circulation model. J Geophys Res 111:D06208

Mitchell T, Jones P (2005) An improved method of constructing a database of monthly climate observations and associated highresolution grids. Int J Climatol 25:693-712

Mo K, Paegle J, Higgins R (1997) Atmospheric processes associated with summer floods and droughts in the central United States. J Clim 10:3028-3046

Nigam S, Ruiz-Barradas A (2006) Seasonal hydroclimate variability over North America in global and regional reanalyses and AMIP Simulations: a mixed assessment. J Clim 19:815-837

Rayner N, Parker D, Horton E, Folland C, Alexander L, Rowell D, Kent E, Kaplan A (2003) Global analyses of sea surface temperature, sea ice, and night marine air temperature since the late nineteenth century. J Geophys Res 108:4407

Saha S, Nadiga S, Thiaw C, Wang J, Wang W, Zhang Q, Van den Dool H, Pan H, Moorthi S, Behringer D, et al (2006) The NCEP climate forecast system. J Clim 19:3483-3517

Schmidt G, Ruedy R, Hansen J, Aleinov I, Bell N, Bauer M, Bauer S, Cairns B, Canuto V, Cheng Y, et al. (2006) Present-day atmospheric simulations using GISS ModelE: comparison to in situ, satellite, and reanalysis data. J Clim 19:153-192

Schubert S, Gutzler D, Wang H, Dai A, Delworth T, Deser C, Findell K, Fu R, Higgins W, Hoerling M, et al (2009) A US CLIVAR project to assess and compare the responses of global climate models to drought-related SST forcing patterns: overview and results. J Clim 22:5251-5272

Schubert S, Suarez M, Pegion P, Koster R, Bacmeister J (2004a) Causes of long-term drought in the US Great Plains. J Clim 17:485-503

Schubert S, Suarez M, Pegion P, Koster R, Bacmeister J (2004b) On the cause of the 1930s Dust Bowl. Science 303:18551859

Seager R (2007) The turn of the century North American drought: global context, dynamics, and past analogs. J Clim 20:55275552

Seager R, Harnik N, Kushnir Y, Robinson W, Miller J (2003) Mechanisms of hemispherically symmetric climate variability. J Clim 16:2960-2978

Seager R, Harnik N, Robinson W, Kushnir Y, Ting M, Huang H, Velez J (2005a) Mechanisms of ENSO-forcing of hemispherically symmetric precipitation variability. Q J R Meteorol Soc 131(608):1501-1528 
Seager R, Kushnir Y, Herweijer C, Naik N, Velez J (2005b) Modeling of tropical forcing of persistent droughts and pluvials over Western North America: 1856-2000. J Clim 18:4065-4088

Seager R, Kushnir Y, Ting M, Cane M, Naik N, Miller J (2008) Would advance knowledge of 1930s SSTs have allowed prediction of the Dust Bowl Drought? J Clim 21:3261-3281

Sutton R, Hodson D (2005) Atlantic Ocean forcing of North American and European summer climate. Science 309:115

Sutton R, Hodson D (2007) Climate response to basin-scale warming and cooling of the North Atlantic Ocean. J Clim 20:891-907

Trenberth K, Branstator G, Karoly D, Kumar A, Lau N, Ropelewski C (1998) Progress during TOGA in understanding and modeling global teleconnections associated with tropical sea surface temperatures. J Geophys Res Oceans 103

Trenberth K, et al (1997) The definition of El Niño. Bull Am Meteorol Soc 78:2771-2777

Wallace J, Gutzler D (1981) Teleconnections in the geopotential height field during the Northern Hemisphere winter. Mon Weather Rev 109:784-812
Wang C, Enfield D, Lee S, Landsea C (2006) Influences of the Atlantic warm pool on Western Hemisphere summer rainfall and Atlantic hurricanes. J Clim 19:3011-3028

Wang H, Schubert S, Suarez M, Koster R (2010) The physical mechanisms by which the leading patterns of SST variability impact US precipitation. J Clim

Weaver S, Nigam S (2008) Variability of the Great Plains low-level jet: large-scale circulation context and hydroclimate impacts. J Clim 21:1531-1551

Weaver S, Schubert S, Wang H (2009) Warm season variations in the low-level circulation and precipitation over the central United States in observations, AMIP simulations, and idealized SST experiments. J Clim 22:5401-5420

Wood K, Overland J (2009) Early 20th century arctic warming in retrospect. Int J Climatol

Yoo J, Zeng N (2010) An atlantic influence on amazon rainfall. Clim Dyn 34(2-3) 